This item was submitted to Loughborough's Research Repository by the author.

Items in Figshare are protected by copyright, with all rights reserved, unless otherwise indicated.

\title{
Nano and microscale contact characteristics of tribofilms derived from fully formulated engine oil
}

PLEASE CITE THE PUBLISHED VERSION

https://doi.org/10.1016/j.triboint.2018.11.007

PUBLISHER

(C) Elsevier

VERSION

AM (Accepted Manuscript)

\section{PUBLISHER STATEMENT}

This paper was accepted for publication in the journal Tribology International and the definitive published version is available at https://doi.org/10.1016/j.triboint.2018.11.007.

\section{LICENCE}

CC BY-NC-ND 4.0

\section{REPOSITORY RECORD}

Umer, Jamal, Nick Morris, Michael Leighton, Ramin Rahmani, Sashi Balakrishnan, and Homer Rahnejat. 2019. "Nano and Microscale Contact Characteristics of Tribofilms Derived from Fully Formulated Engine Oil". figshare. https://hdl.handle.net/2134/36042. 


\title{
Nano and microscale contact characteristics of tribofilms derived from fully formulated engine oil
}

\author{
Jamal Umer ${ }^{1}$, Nick Morris $^{1 *}$, Michael Leighton ${ }^{1}$, Ramin Rahmani ${ }^{1}$, Sashi Balakrishnan ${ }^{2}$, Homer Rahnejat $^{1}$ \\ ${ }^{1}$ Wolfson school of Mechanical, Electrical and Manufacturing Engineering, Loughborough University, \\ Leicestershire, UK \\ ${ }^{2}$ Castrol Ltd., BP Technology Centre, Whitchurch Hill, Pangbourne, Berkshire, UK \\ *Corresponding author: N.J.Morris@lboro.ac.uk
}

\begin{abstract}
A systematic approach is required in order to determine the frictional characteristics of a contacting pair in the presence of a tribofilm. Despite the clear benefits in functionality and in reducing wear, the generation of ZDDP-based tribofilms often lead to increased frictional losses. Such an increase is also observed in the tribometric tests reported here, as well as in open literature. This paper investigates the underlying mechanics for the rise in friction using an integrated methodology, based upon Atomic Force Microscopy (AFM) and X-ray Photoelectron Spectroscopy (XPS). The use of an analytical contact mechanics model demonstrates that the pressure coefficient of boundary shear strength, measured using lateral force microscopy, provides an explanation for the observed increase in measured friction at micro-scale.
\end{abstract}

Keywords: AFM in Lateral Force Mode (LFM); Tribo-film; ZDDP; Friction

\section{Nomenclature}

$A$

Apparent contact area $\left[\mathrm{m}^{2}\right]$

$A_{a}$

Asperity contact area $\left[\mathrm{m}^{2}\right]$

$b$

Axial contact face-width of the sliding strip [m]

E

Young's modulus of elasticity [Pa]

$E^{*}$

Composite (effective) Young's modulus of elasticity of the contact [Pa]

$E_{a}$

Activation energy $[\mathrm{J}]$

F

Applied force $[\mathrm{N}]$

$F_{5 / 2}, F_{2}$

Statistical Functions [-]

$F_{a}$

Adhesive force $[\mathrm{N}]$

$f$

Total friction $[\mathrm{N}]$

$f_{b}$

Boundary friction $[\mathrm{N}]$

$f_{v}$

Viscous friction $[\mathrm{N}]$

$h_{0}$

Minimum film thickness [m] 


$\begin{array}{ll}k & \text { Growth Rate }\left[\mathrm{ms}^{-1}\right] \\ k_{b} & \text { Boltzmann Constant }[\mathrm{J} / \mathrm{K}] \\ l & \text { Lateral width of the contact }[\mathrm{m}] \\ p & \text { Contact pressure [Pa] } \\ \overline{\mathrm{P}} & \text { Dimensionless load parameter [-] } \\ R & \text { Radius of curvature of the slider face-width or AFM tip [m] } \\ T & \text { Absolute temperature [K] } \\ U & \left.\text { Sliding velocity [ms }{ }^{-1}\right] \\ W & \text { Total applied load/total contact reaction force }[\mathrm{N}] \\ W_{a} & \text { Load carried by the asperity tips }[\mathrm{N}] \\ W_{h} & \text { Hydrodynamic reaction }[\mathrm{N}] \\ w & \left.\text { Work of Adhesion [Jm }{ }^{-2}\right] \\ z_{0} & \text { Atomic equilibrium separation }[\mathrm{m}]\end{array}$

Greek Letters

$\varepsilon$

$\delta$
Convergence criteria [-]

Elastic compression of contacting pair [m]

Activation volume $\left[\mathrm{m}^{3}\right]$

Number of asperity peaks per unit area $\left[\mathrm{m}^{-2}\right]$

Lubricant dynamic viscosity $[\mathrm{Pa} . \mathrm{s}]$

Average radius of curvature of asperity tips [m]

Elasticity parameter [-]

Stribeck oil film parameter [-]

Poisson's ratio [-]

Composite surface roughness of counter face surfaces [m]

Pressure coefficient of boundary shear strength [-]

Pressure coefficient of boundary shear strength measured under dry LFM [-]

Pressure coefficient of boundary shear strength measured under wet LFM [-]

Shear stress $[\mathrm{Pa}]$ 


$\begin{array}{ll}\tau_{a} & \text { Shear stress of asperity junctions }[\mathrm{Pa}] \\ \tau_{0} & \text { Eyring shear stress }[\mathrm{Pa}] \\ \Gamma & \text { Pre-exponential factor }[\mathrm{m} / \mathrm{s}]\end{array}$

\section{Abbreviations}

$\begin{array}{ll}\text { AFM } & \text { Atomic Force Microscope } \\ \text { AISI } & \text { American Iron and Steel Institute } \\ \text { ASTM } & \text { American Society of Testing Materials } \\ \text { DMT } & \text { Derjaguin-Muller-Toporov } \\ \text { EHL } & \text { Elastohydrodynamic Lubrication } \\ \text { JKR } & \text { Johnson-Kendall-Roberts } \\ \text { LFM } & \text { Lateral Force Microscopy } \\ \text { MD } & \text { Maugis-Dugdale } \\ \text { MoDTC } & \text { Molybdenum Dialkyldithiocarbamate } \\ \text { RMS } & \text { Root Mean Square } \\ \text { TMR } & \text { Trace Minus Retrace } \\ \text { VI } & \text { Viscosity Index } \\ \text { XPS } & \text { X-ray Photoelectron Spectroscopy } \\ \text { ZDDP } & \text { Zinc Dialkyldithiophosphates }\end{array}$

\section{Introduction}

An overarching challenge for the automotive industry is the improvement of fuel efficiency and the reduction of harmful emissions. The frictional losses in internal combustion engines used to power commercial passenger vehicles account for $15-20 \%$ of the total engine losses [1,2]. Under particular harsh operating conditions, experienced in urban driving, these losses can increase to 20-30\%. Of the aforementioned losses, 45\% are attributed to the piston-cylinder system [1], with the piston compression ring-bore interface accounting for 7-8\% of all the losses within the engine [3-5]. This clearly presents a significant opportunity to improve system efficiency through reducing in-cylinder frictional losses [6].

The top piston compression ring has the primary function of acting as an effective seal between the piston and the cylinder wall [7]. It is pressed onto the wall through a combination of gas pressure loading and elastic ring tension. Inevitably the loaded conjunction generates friction when subjected to relative sliding motion [7,8]. At piston mid-stoke the interfacial friction is palliated due to the generation of a hydrodynamic film. However, at piston reversals, lubricant entrainment ceases momentarily and direct interaction of rough contiguous surfaces occurs. The role of surface-active lubricant additives and the tribofilm formation is critical in controlling friction and wear [9]. The 
synergistic and antagonistic behaviour of additive species at the contacting surfaces is determined through the competitive process of tribofilm formation [10,11].

One of the most common chemical compounds added to automotive engine lubricants is zinc dialkyldithiophosphates (ZDDP). In the period 1930s-1950s, ZDDP was used for its anti-oxidation and corrosion-inhibiting properties [12]. By the mid-1950s the anti-wear benefit had become apparent, particularly in the cam-tappet conjunction [13, 14]. Whilst providing excellent anti-wear, corrosion and oxidation resistance, ZDDP has been shown frequently to promote increased friction [15-17].

There have been many studies investigating the mechanism(s) through which a ZDDP tribofilm increases friction. The studies have largely used tribometry [15-17]. Muraki et al [15] used a two roller machine to investigate the influence of surface chemical composition and frictional characteristics at various slide-roll ratios. It was noted that when ZDDP is added to a base oil, in isolation, it reduces surface wear whilst increasing friction. However, in combination with Molybdenum Dialkyldithiocarbamate (MoDTC), the undue effect of generated friction is somewhat mitigated. Several mechanisms have been suggested to account for increased friction in the presence of ZDDP films in mixed and boundary regimes of lubrication. Taylor et al [16] conducted experimental elastohydrodynamic lubrication (EHL) analysis using optical interferometry, using a steel sphere against an optically flat glass disc. They demonstrated that the increased propensity for boundary lubrication was due to the roughening of the contiguous surfaces as a ZDDP tribofilm grows. It is this process which was proposed to be responsible for the associated increase in friction. Later, Taylor and Spikes [17], using a similar experimental configuration, suggested that ZDDP inhibits the entrainment of lubricant at the inlet of an EHL contact, leading to a reduction in lubricant film thickness, and thus increased boundary friction.

The use of nano-scale testing using nano-indentation techniques and Atomic Force Microscopy (AFM) has become an important method for investigating ZDDP-based tribofilms [18-23]. Pidduck and Smith [18] demonstrated the use of an AFM in Lateral Force Microscopy (LFM) as a viable method to investigate tribofilms generated during tribometric tests. Later, analysis of the nanomechanical properties of thermally [19] and thermo-mechanically [20,21,23] activated ZDDP films were conducted. All the studies showed that the generated tribofilm had a lower elastic modulus than the steel substrate to which it was bonded.

Carpick et al [24] showed that the nano-scale frictional properties, measured by AFM in lateral force mode (LFM), are a function of AFM probe's tip radius, reduced elastic modulus of the contact, adhesion and interfacial shear strength of the film. They used a platinum coated silicon nitride tip with a radius of $140 \mathrm{~nm}$ on a mica surface in ultra-high vacuum $\left(<5 \times 10^{-10}\right.$ Torr $)$ at room temperature. Enaschescu et al [25] and Lantz et al [26] showed that friction measured through LFM is linearly proportional to the contact area. Enaschescu et al [25] used atomic force microscopy in an ultra-high vacuum chamber to remove residual moisture and oxygen. A silicon cantilever $(0.23 \mathrm{~N} / \mathrm{m})$ was employed with a tungsten carbide tip $(20 \mathrm{~nm})$, whilst the sample material was made from a single artificial diamond crystal (111) terminated with hydrogen, and slightly doped with Boron. The linearity of the frictional measurement and contact area were demonstrated for normal loads of up to $12 n N$. Enaschescu et al [25] investigated the use of DMT [27] and JKR [28] models. For the conditions investigated they found that the DMT theory provides a better agreement with the measurements. Lantz et al [26] also used ultra-high vacuum AFM on a cleaved $\mathrm{NbSe} 2$ sample with a $12 \mathrm{~nm}$ radius Silicon tip $(1.1 \mathrm{~N} / \mathrm{m})$. The sample and tip were transferred to a vacuum chamber and heated to $120^{\circ} \mathrm{C}$ for 30 minutes before each test. The normal load range during friction measurements 
were between $-20 n N$ to $50 n N$. Lantz et al [26] used the MD theory [29] because of the sharp profile of the tip and the existence of intermediate levels of elastic deformation. Umer et al [30] used lateral force microscopy and nano-scale elasticity measured by AFM for six-cylinder liner bore materials and coatings including Cast Iron, Nickel-Silicon carbide, Diamond Like Carbon (DLC), Plasma Electrolytic Oxide, Iron Molybdenum and Titanium Dioxide. An AFM probe with radius of $20 \mathrm{~nm}$ and spring constant of $0.06 \mathrm{~N} / \mathrm{m}$ was used for LFM, and for nano-scale modulus of elasticity an AFM probe of spring constant $200 \mathrm{~N} / \mathrm{m}$ with tip radius of $8 \mathrm{~nm}$ was used. Umer et al [30] showed that friction is dependent on elastic modulus, surface energy and interfacial shear strength. Carpick et al [24], Enaschescu et al [25], Lantz et al [26] and Umer et al [30] all describe friction measured through LFM as dependent on the real contact area.

A key parameter controlling the contact area between nanometre radius spheres and flat sample surfaces is the elastic modulus. The nano-scale elasticity of the tribofilm formed in sliding contacts is therefore a useful parameter to characterise the tribofilm behaviour [21,31,32]. Aktary et al [21] used nano-indentation with a maximum load of $100 \mu N$ to measure nano-scale elasticity of a ZDDP tribofilm, generated by rubbing a stainless-steel pin on a 52100-steel sample in the presence of a lubricant. They showed that the average nano-scale elasticity of tribofilm is $92.6 \mathrm{GPa}$ and is relatively independent of the rubbing period, but varies spatially with variations of local asperity contact pressure. Pereira et al [31] used a high frequency wear tester to generate a ZDDP tribofilm on 52100steel samples at temperature range: $25^{\circ} \mathrm{C}-200^{\circ} \mathrm{C}$. The nano-scale elasticity measured for the tribofilm was fairly consistently $100 \mathrm{GPa}$, until a temperature of $150^{\circ} \mathrm{C}$, after which it dropped to $75 \mathrm{GPa}$ at $200^{\circ} \mathrm{C}$. Nicholls et al [32] used A319 aluminium and AISI 52100-steel samples and a Cameron-Plint high frequency friction tester in the presence of an oil containing 1.2\% ZDDP. The tribofilm is generated by sliding for $1 \mathrm{~h}$ at $100^{\circ} \mathrm{C}$. The nano-scale elasticity was measured at edges and centre of discs with values of $53.7 \pm 14.7 \mathrm{GPa}$ and $112.4 \pm 18.5 \mathrm{GPa}$ respectively.

Friction as a major source of power loss in tribological contacts should be minimised for enhanced performance in most applications. Due to the scale-dependent nature of friction [33-35], it is crucial to investigate the origin sources of friction at nano-scale. Thus, a multi-scale approach should be developed to fundamentally understand the observed/measured micro-scale friction. The properties of tribofilms formed in tribological contacts and measured at asperity level interactions strongly influence the frictional behaviour at higher system level interactions.

In the current paper a reciprocating tribometer is used to activate the lubricant additives to form surface films. The main aim is to examine the interfacial shear strength of the additives adsorbed onto the surfaces and quantify their effect. Test conditions were chosen to focus upon tribofilms derived from a fully formulated engine oil, formed primarily through mechanical activation. The nano-scale elasticity of the surface films were shown to be in good agreement with published literature $[21,31,32]$. In addition, LFM is used to characterise the interfacial shear strength of the adsorbed film. The nano-scale characteristics, such as the interfacial shear strength of the tribofilm, are explained through micro-scale relations for organic films [36]. Furthermore, the significance of measured interfacial shear strength in determining the boundary friction in micro-scale is highlighted.

\section{Methodology}

A multi-stage procedure is followed in order to investigate the performance of tribofilm derived from the fully formulated engine oil (figure 1). The experimental procedure is divided into three stages: lubricated (wet), pre-tribometry test (dry) and post-tribometry test (dry). In a pre-tribometry test (dry), the virgin surfaces are characterised and benchmarked before the formation of a tribofilm. The 
characterisation of surfaces is carried out through infinite focus variation microscopy, atomic force microscopy, force-displacement analysis by AFM and x-ray photoelectron spectroscopy. In lubricated (wet) stage, a tribo-film is generated and the frictional performance at the micro-scale is determined through use of a precision sliding-strip tribometer. Then, lateral force microscopy is performed to find the frictional characteristics at nano-scale in the presence of the lubricant. In the post-tribometry test (dry) stage, the lubricant layer is removed and the remaining tribofilm is characterised and compared with the previously benchmarked samples. The nano-scale investigation is conducted through use of AFM and XPS in order to ascertain the evolved changes to the surface elasticity and shear strength. The parameters measured from each experimental technique are also shown in figure 1 . The measured parameters for the single asperity nano-scale conjunction are shown to be influential at micro-scale through their inclusion in an analytical contact mechanics model which includes the interfacial shear strength.
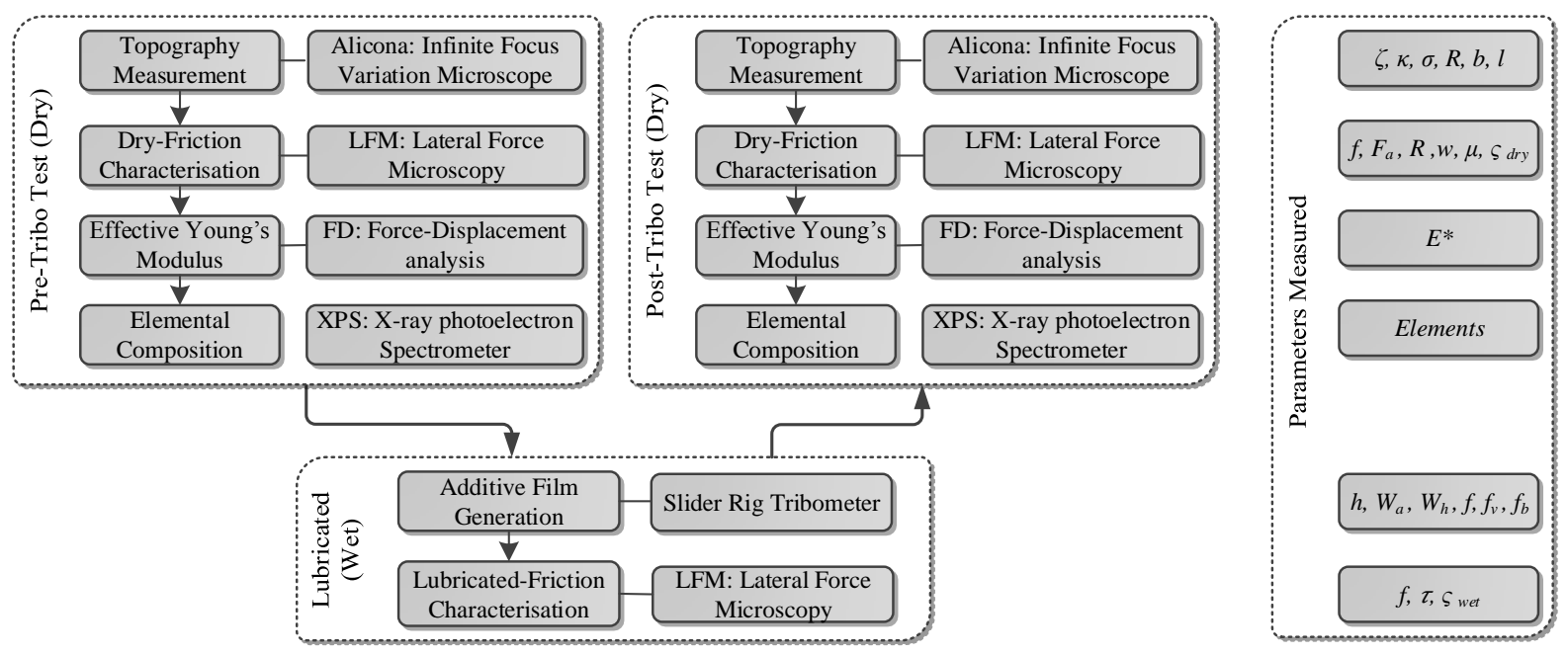

Figure 1: Experimental procedure and measured parameters

\subsection{Micro-scale tribometry}

A reciprocating sliding-strip tribometer, shown in Figure 2, is used to reproduce specific piston compression ring-liner contact conditions at top dead centre reversal in transition from compression to power stroke [37-39]. Generated friction is measured using a floating plate, mounted upon ultra-low friction bearings. A flat test sample with characteristics similar to the piston liner surface is mounted upon the floating plate. The floating plate experiences a force generated by the loaded contact friction between the sliding strip (of the same face-width geometrical profile as a compression ring) and driven through a backlash free leadscrew with the test sample. The resulting inertial force is measured directly by high precision piezoelectric load cells. $1 \mathrm{ml}$ of lubricant was supplied onto the surface of the test specimen and uniformly spread upon its surface by a few initial strokes of the loaded sliding strip. Subsequently, a total of 40 strokes were conducted for each test. This number of strokes was chosen to prevent any significant change to the surface topography, isolating the effect of the formed tribofilm on the frictional performance (table 2). 


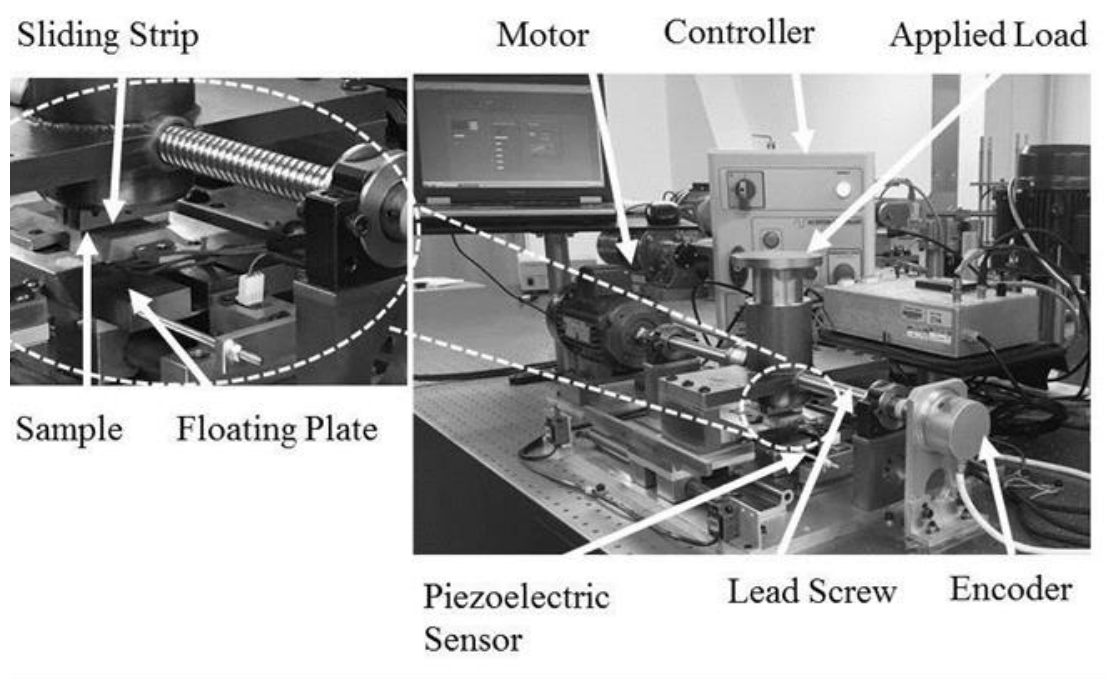

Figure 2: The sliding strip tribometer

At elevated temperatures, a thermally activated tribofilm is expected to form on the surface of the test specimen [40]. Significant differences in mechanical performance of thermally and mechanically activated films have been reported by Gosvami et al [41]. To allow for the investigation of the generated films solely due to mechanical activation process at the contacting asperities with the potential to influence boundary friction, the experiments were conducted at the ambient room temperature of $20^{\circ} \mathrm{C}$.

The mechanical and thermal energy present in the contact can be shown to produce an appreciable tribofilm growth rate. Akchurin and Bosman [42] showed that the Arrhenius equation with an additional shear activation energy term can be used to describe the rate limiting step, controlling the growth of the tribofilm as:

$k=\Gamma e^{-\left(\frac{E_{a}-\tau \Delta V}{k_{b} T}\right)}$

where, $\tau$ is shear stress $[\mathrm{Pa}], k_{b}$ is Boltzmann constant $[\mathrm{J} / \mathrm{K}]$ and $T$ is absolute temperature $[\mathrm{K}]$. The typical values for the factor $\Gamma$, activation energy, $E_{a}$ and activation volume, $\Delta V$ for growth of a ZDDP film are $0.01 \mathrm{~nm} / \mathrm{s}, 1.12 \times 10^{-19} \mathrm{~J}$ and $3.80 \times 10^{-29} \mathrm{~m}^{3}$ respectively [41,42]. For new surface pairs (such as those in the current experiments) some of the asperities deform plastically through running-in conditions. Ignoring any wear/removal of the tribofilm for the purpose of initial calculations, the locations of plastic yield would have a growth rate of $0.1-1.0 \mathrm{~nm} / \mathrm{s}$ for the typical values of $\Gamma, E_{a}$ and $\Delta V$ stated above. Therefore, it is reasonable to assume that the test conditions (described below) are suitable to induce growth of a tribofilm. This is confirmed later through elemental spectroscopy of the surfaces of the tested samples.

Table 1 provides the operating conditions used in the tribometric tests. The load and sliding speeds are chosen to reproduce the operating conditions experienced by the top compression ring - liner contact in the vicinity of the top dead centre reversal in terms of contact pressure and sliding speed. The load intensity, typical of the beginning of the power stroke, was measured by Morris et al [6] to be in the range 500-852 N/m for high performance race engines. The sliding speeds are representative of the piston (ring) speed during the first few crank angle rotations prior and post idling condition. However, it should be noted that the conditions in the sliding rig contact do not reflect some other in-situ engine conditions, such as the prevailing liner temperature and any lubricant squeeze film effect, as well as 
any contact inlet lubricant starvation. Therefore, the focus is put upon the effect of contact pressure and sliding shear conditions only.

Table 1: Experimental conditions

\begin{tabular}{|l|c|c|}
\hline Parameter & Value & Unit \\
\hline Load per unit length & $777 \pm 9$ & $\mathrm{~N} / \mathrm{m}$ \\
\hline Sliding speed & $(13.0-27.0) \pm 0.2$ & $\mathrm{~mm} / \mathrm{s}$ \\
\hline Stroke length & $23.0 \pm 0.1$ & $\mathrm{~mm}$ \\
\hline Strip width $(b)$ & $1.00 \pm 0.01$ & $\mathrm{~mm}$ \\
\hline Strip length $(l)$ & $32.00 \pm 0.01$ & $\mathrm{~mm}$ \\
\hline Profile radius $(R)$ & $12.5 \pm 0.3$ & $\mathrm{~mm}$ \\
\hline
\end{tabular}

The tribological conjunction under investigation comprises two ground surfaces: a flat AISI 4140 steel test specimen and an AISI 440C steel sliding strip. The running surface of the sliding strip has a parabolic profile in the direction of sliding to simulate the barrel-shape profile of a piston compression ring. The flat test specimen and sliding strip were machined to represent surface topography in line with typical roughness parameters found in ring and liner surfaces [43]. However, no cross-hatching is carried out on the test specimen, which is usually used on liner surface. The existence of crosshatch features on the surface will add complexity to the measurements, particularly when using AFM in lateral force mode [44]. The surface roughness for the counter face surfaces before and after each test is provided in table 2 . The errors associated with the roughness values are reduced to significant numbers.

Table 2: Roughness of contacting surfaces

\begin{tabular}{|l|l|l|l|}
\hline \multirow{2}{*}{$\begin{array}{l}\text { RMS surface } \\
\text { roughness }\end{array}$} & \multicolumn{2}{|c|}{ Value } & Unit \\
\cline { 2 - 4 } & Before test & After test & \\
\hline Test specimen (Plate) & $0.67 \pm 0.02$ & $0.68 \pm 0.02$ & $\mu \mathrm{m}$ \\
\hline Sliding strip & $0.33 \pm 0.02$ & $0.34 \pm 0.03$ & $\mu \mathrm{m}$ \\
\hline
\end{tabular}

A thorough cleaning procedure is carried out for each test specimen. Before mounting the specimen onto the tribometer, they were thoroughly cleaned for 10 minutes in an ultrasound bath with petroleum ether 40-60. After testing, the samples were again washed with petroleum ether 40-60 to remove any hydrocarbon residue, leaving only any bonded/adsorbed tribofilm. Although the petroleum ether evaporates rapidly at room temperature, samples were further dried with application of hot air flow to expedite the evaporation process. While it is possible that some residue of the petroleum ether may still reside on the surface, this is deemed to be trivial, particularly when considering that the engine oil does not include any residue of petroleum ether.

A typical fully-formulated 5W30 engine lubricant and a base oil were used during the tests. The slider rig apparatus is designed to operate within the load range of $500-852 \mathrm{~N} / \mathrm{m}$ to produce the necessary conditions for boundary and mixed-boundary regimes of lubrication. Therefore, the hydrodynamic reaction plays a negligible role in affecting the overall load carrying capacity and generated friction [37-39]. The difference in the lubricant viscosities was incorporated into the model to further demonstrate this minor effect. A partial elemental composition of the 5W30 formulated lubricant is provided in table 3 . The critical components are a calcium-based detergent and multi-functional ZDDP additive. The bulk rheological parameters of both the base oil and the fully formulated 
lubricant are given in table 4. The viscosity data was measured through the standard ASTM D445 and VI [45]. The uncertainty of the lubricant density is indicated by the number of significant figures.

Table 3: Fully formulated oil elemental composition

\begin{tabular}{|c|c|c|}
\hline Element & Concentration & Unit \\
\hline Calcium & 1980 & $p p m$ \\
\hline Phosphorus & 780 & $p p m$ \\
\hline Sulphur & 2600 & $p p m$ \\
\hline Zinc & 900 & $p p m$ \\
\hline
\end{tabular}

Table 4: Bulk lubricant rheological parameters

\begin{tabular}{|c|c|c|c|}
\hline Oil type & Parameter & Value & Unit \\
\hline \multirow{3}{*}{ Fully formulated } & Density at $15^{\circ} \mathrm{C}$ & $0.846 \pm 0.001$ & $\mathrm{~g} / \mathrm{ml}$ \\
\cline { 2 - 4 } & Kinematic viscosity at $40^{\circ} \mathrm{C}$ & $52.05 \pm 0.11$ & $\mathrm{cSt}$ \\
\cline { 2 - 4 } & Kinematic viscosity at $100^{\circ} \mathrm{C}$ & $9.48 \pm 0.06$ & $\mathrm{cSt}$ \\
\cline { 2 - 4 } & Base Number & 6.5 & $\mathrm{Mg} / \mathrm{g} \mathrm{KOH}$ \\
\hline \multirow{3}{*}{ Base } & Density at $15^{\circ} \mathrm{C}$ & $0.835 \pm 0.001$ & $\mathrm{~g} / \mathrm{ml}$ \\
\cline { 2 - 4 } & Kinematic viscosity at $40^{\circ} \mathrm{C}$ & $19.71 \pm 0.10$ & $\mathrm{cSt}$ \\
\cline { 2 - 4 } & Kinematic viscosity at $100^{\circ} \mathrm{C}$ & $4.27 \pm 0.10$ & $\mathrm{cSt}$ \\
\hline
\end{tabular}

The test procedure also includes topographical measurement of all test specimens in order to ensure repeatability for all the tests. The measurements were carried out using an Alicona G4 applying focus variation technique. The Alicona G4 has a vertical resolution of $50 \mathrm{~nm}$ and a lateral resolution (along the surface) of $0.81 \mu \mathrm{m}$ for $20 \times$ optical zoom on a scanning area of $715 \times 544 \mu \mathrm{m}^{2}$. This area is much larger than the area scanned in LFM measurements; i.e. $1 \times 1 \mu m^{2}$. The smaller scanning length of AFM excludes longer wavelengths and hence reduces the RMS roughness measured using this technique to $8 \pm 2 \mathrm{~nm}$. This is typical of RMS roughness measured using AFM in the literature [46-49].

\subsection{Nano-scale experimental approach}

AFM has been used extensively for tribological investigations as it allows for highly sensitive measurements of surface forces at a scale similar to those of a single asperity [50-56]. The pressure coefficient of boundary shear strength of a surface, $\varsigma$ relates the boundary shear stress at the AFM tipsample conjunction to the applied load. This was required for the predictive analysis of boundary friction described in section 2.4. The nano-scale measurements are carried out using a Veeco Dimension 3100 AFM.

Measurement of two parameters is of particular importance when using an AFM to determine adhesive friction at the tip-specimen surface contact. One is the pressure coefficient of boundary shear strength, $\varsigma$ and the other is the reduced (effective) elastic modulus of the contacting surfaces, $E^{*}$; taking into account the effect of any tribo-film present. This makes a significant difference to the 
accuracy of predicted boundary friction [30] as it affects the calculated asperity load carrying capacity through equation (9).

LFM was used to measure the lateral (friction) forces on a scanning tip, using the Trace Minus Retrace (TMR) method [53]. LFM applies TMR by raster scanning the tip across the surface, with the scan direction perpendicular to its cantilever length. The local surface roughness effects can then be filtered from the contact friction data by taking the difference between the trace and retrace scans and averaging the same. The tip radius was measured using a calibrated artefact of known geometry and applying a deconvolution procedure prior to each measurement. Prior to measurements, the AFM probe was calibrated using the "blind" calibration method, by scanning a surface with known frictional properties in order to determine a general calibration factor [57].

The LFM measurements were conducted at 6 different locations for each sample, with each scanned area being $1 \times 1 \mu \mathrm{m}^{2}$. All scans were conducted with a DNP-10 $S i_{3} N_{4}$ tip with a nominal tip radius of $20 \mathrm{~nm}$ and a cantilever spring constant of $0.12 \mathrm{~N} / \mathrm{m}$. The applied contact loads were in the range $20-120 \mathrm{nN}$. The humidity was controlled at a relative humidity of $50 \pm 5 \%$.

To obtain the reduced elastic modulus of the contact, a force displacement analysis was conducted. The tip radius was measured by taking topographical measurements of a calibration artefact. The AFM was then operated as a nano-indenter by loading the tip-surface contact and measuring the distance when the probe is lowered towards the surface, as well as the deflection of its cantilever support. More information on this procedure is reported by Umer et al [30]. The indentation measurements were conducted using RTESP-525 $\mathrm{Si}_{3} N_{4}$ tips with a cantilever stiffness of $200 \mathrm{~N} / \mathrm{m}$ and a nominal tip radius of $8 \mathrm{~nm}$ (measured to be $11.1 \mathrm{~nm}$ ). Measurements were conducted in 4 locations across the surface before tribometric tests (section 2.1). A total of 9 positions were measured after tribometry. This allowed for the detection of any potential variations in measurements resulting from the formation of an intermittent tribo-film.

By using contact mechanics theory, measured force-distance curves and TMR data from LFM, the two stated key parameters, $\varsigma$ and $E^{*}$ are determined. The procedure is described in section 2.3

\subsection{Nano-Scale analytical contact mechanics model}

It is necessary to determine the most applicable model to approximate the mechanics of tip-surface contact. The adhesive forces are promoted by the close-range surface energy of the materials, for which the continuum contact mechanics models proposed by Bradley [58], Johnson et al [28] (JKR), Derjaguin et al [27] (DMT) and the broader variant by Maugis [29] may be employed. To determine the applicability of these models, two non-dimensional parameters are commonly used [59].

Firstly, an elasticity (Tabor) parameter $\mu$ was used, which represents the ratio of elastic deformation resulting from an adhesive disengagement from a surface to the range of surface forces as [60]:

$\mu=\left(\frac{R w^{2}}{E^{*^{2}} z_{0}^{3}}\right)^{1 / 3}$

where, $w$ is the work of adhesion, $R$ is the reduced radius of a pair of non-conforming contacting ellipsoidal solids (in this case a hemispherical tip contacting a semi-infinite elastic half-space: a flat specimen). Therefore, $R$ is simply the tip radius of the AFM probe. $z_{0}$ is the atomic equilibrium separation between the two surfaces and the reduced elastic modulus, $E^{*}$ of the contact is:

$E^{*}=\left(\frac{1-v_{1}^{2}}{E_{1}}+\frac{1-v_{2}^{2}}{E_{2}}\right)^{-1}$ 
The second dimensionless parameter is the load parameter, $\bar{P}$ which is the ratio of applied normal load to the adhesive force:

$\bar{P}=\frac{F}{\pi w R}$

The Tabor parameter and the dimensionless load parameter indicate the importance of the adhesive forces relative to the elastic deformation forces of the surface. This can be seen graphically on the Greenwood adhesion map [59]. In this study the DMT model was found to be the most suitable contact mechanics model for the prevailing conditions. This outcome is in line with the findings of Enachescu et al [25] who used a similar analysis for DLC coated surfaces. The DMT model has been used to predict the tip-sample contact area as [30]:

$A=\pi\left[\frac{3 R\left(F-F_{a}\right)}{4 E^{*}}\right]^{2 / 3}$

where, $F_{a}$ is the adhesive force and in the case of measurements in dry contact conditions it includes adhesion as well as the effect of meniscus force caused by a condensed layer of a water film. It should be noted that a mono-layer of water is condensed on any surface in $25 \mu \mathrm{s}$, even in low relative humidity environments $[61,62]$. Therefore, the meniscus force contribution should be considered. For lubricated contacts (fluid cell AFM), the pull-off force and adhesion are negligible and meniscus forces are kept at a sufficient distance from the tip to ensure their effect is negligible. Under such conditions, equation (5) simplifies to the classical Hertzian condition with $F_{a}=0$.

Once friction is determined, the interfacial shear strength of the contact can be calculated. The reduced elastic modulus of the contact can be determined by combining the measured data from force distance curves and the DMT theory as [30]:

$E^{*}=\frac{3}{4} \frac{\left(F-F_{a}\right)}{\sqrt{R \delta^{3}}}$

The average contact pressure is obtained as:

$p=\frac{F-F_{a}}{A}$

\subsection{Micro-scale analytical contact model}

Nano-scale measurements of the pressure coefficient of boundary shear strength (section 2.3) were carried out and used in an analytical model representing the micro-scale tribometric tests. These provide data for prediction of friction at micro-scale which can then be compared with those directly measured through tribometry.

The hydrodynamic load carrying capacity was calculated using a one-dimensional analytical solution of Reynolds equation, yielding [63]:

$W_{h}=\frac{4.9 \eta l U R}{h_{o}}$

where, $h_{0}$ is the minimum film thickness and $R$ is the radius of curvature of the ring contact face profile. The one-dimensional assumption is deemed suitable as the length of the sliding strip $l$ in the lateral direction (i.e. transverse to the direction of entraining motion) is significantly longer than its face-width $b$ in the direction of entraining motion; providing a ratio of $l / b>30$. Therefore, the side leakage flow along the strip length can be neglected [63]. The schematic representation of slider strip and flat specimen is shown in the figure 3. 


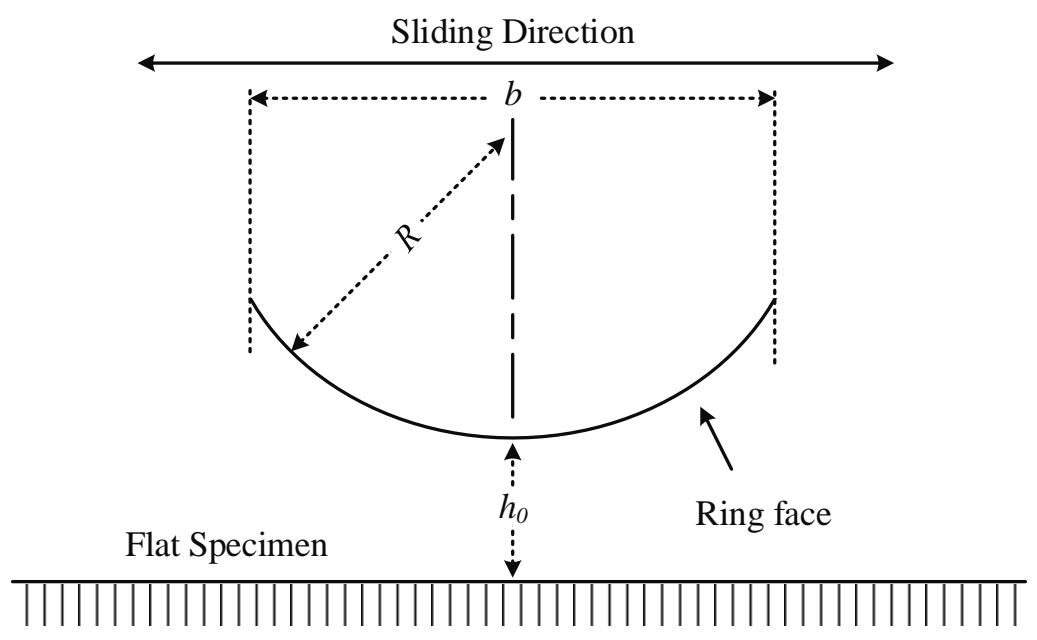

Figure 3: Schematic representation of slider strip and flat specimen

Considering the examined range of sliding speed and applied load combinations, it is anticipated that there would be a significant degree of boundary interactions. Asperity load carrying capacity and contact area can be evaluated using the Greenwood and Tripp [64] model. The roughness parameters $\zeta \kappa \sigma$ and the ratio $\sigma / \kappa$ were measured using $3 \mathrm{D}$ optical focus variation technique, yielding the values $0.003 \pm 0.001$ and $0.06 \pm 0.01$ respectively. $\zeta$ is the number of asperities per unit area, $\kappa$ is the average radius of curvature of asperity tips and $\sigma$ is the composite surface roughness of counter face surfaces. The statistical parameters $F_{5 / 2}$ and $F_{2}$ are determined through a polynomial curve fit [65]. The $F_{5 / 2}$ and $F_{2}$ polynomial functions for the measured test specimens are provided in the appendix. Bulk material properties provided by the material supplier are used for calculating the composite Young's modulus of elasticity $E^{*}$ for the micro-scale analysis. This results in a value of the composite elastic modulus of $108 \mathrm{GPa}$. The load carried by the asperities and the real contact area can be calculated as [64]:

$W_{a}=\frac{16 \sqrt{2}}{15} \pi l(\zeta \kappa \sigma)^{2} \sqrt{\frac{\sigma}{\kappa}} E^{*} \int_{-b / 2}^{b / 2} F_{5 / 2}(\lambda) d x$

$A_{a}=\pi^{2} l(\zeta \kappa \sigma)^{2} \int_{-b / 2}^{b / 2} F_{2}(\lambda) d x$

where, $W_{a}$ is load carried by the asperity tips, $A_{a}$ is the asperity contact area and $\lambda$ is the Stribeck oil film parameter determined as: $\lambda=h / \sigma$.

For instantaneous quasi-static equilibrium, the combined hydrodynamic reaction and the load carried by the asperities equilibrate the applied contact load, thus:

$W=W_{a}+W_{h}$

where, $W$ is the total applied load and $W_{h}$ is the hydrodynamic reaction. Since the gap between the two surfaces is not known a priori, an iterative approach is employed. An initial guess is made for the minimum film thickness, $h_{0}$, and the total contact reaction, $W$, is obtained. The convergence criterion is:

$\frac{W-F}{F} \leq \varepsilon$

where, $F$ is the applied load, and $\varepsilon=10^{-4}$ is the error tolerance.

If the criterion is not met, then $h_{0}$ is adjusted as [66]: 
$h_{0}^{n}=(1+B \vartheta) h_{0}^{n-1}$

where, $n$ is an iteration counter, and $B$ is a damping coefficient with a typical value of 0.005 for the current analysis, and $\vartheta=(W-F) / \max \{W, F\}$.

The iterative procedure continues until the convergence criterion in equation (12) was satisfied.

Once the lubricant film thickness and thus, the load carried through asperity interactions and hydrodynamic reaction are determined, together with the asperity contact area through equation (10), the generated friction can be predicted. The boundary shear stress is obtained as [67]:

$\tau_{a}=\tau_{0}+\varsigma p$

where, $\varsigma$ is the pressure coefficient of boundary shear strength of surface asperities, measured through use of AFM in lateral force mode; LFM (see section 2.3). For many practical applications due to the magnitude of the pressures at asperity conjunctions the boundary friction is dominated by the pressure dependent term in equation (14). Therefore, for the current study it is assumed that the boundary friction takes the Coulombic form, thus:

$f_{b}=\tau_{0} A_{a}+\varsigma W_{a} \approx \varsigma W_{a}$

In the overall contact domain any contribution due to viscous shear of lubricant film is as the result of Couette flow, thus:

$f_{v}=l \int_{-b / 2}^{b / 2} \frac{\eta \Delta U}{h} d x$

Therefore, the total friction becomes:

$f=f_{v}+f_{b}$

Micro-scale predictions have been compared with measured friction recorded from the sliding strip tribometer (section 3).

\section{Results and Discussion}

The test conditions in the sliding tribometric study promote predominantly mixed and boundary regimes of lubrication as the tribometer simulates the conditions pertaining to piston top dead centre reversals [4]. Each experiment was repeated 3 times, each time with a new sample. The measured data was then averaged.

The results for the experiments carried out at operating parameters given in the table 1 are shown in figure 4. These are for lubricated conditions using the 5W30 fully formulated lubricant and a base oil. The value of coefficient of friction is indicative of mixed or boundary regimes of lubrication $[4,38]$. Friction changes direction with motion reversal at end of outward and return strokes. At either end of stroke, the coefficient of friction attains its maximum static value because of momentary cessation of sliding motion at reversals. The average value of coefficient of friction from each of the measurements is calculated by averaging the steady friction values without any contribution from the static coefficient of friction observed during the motion reversals. 


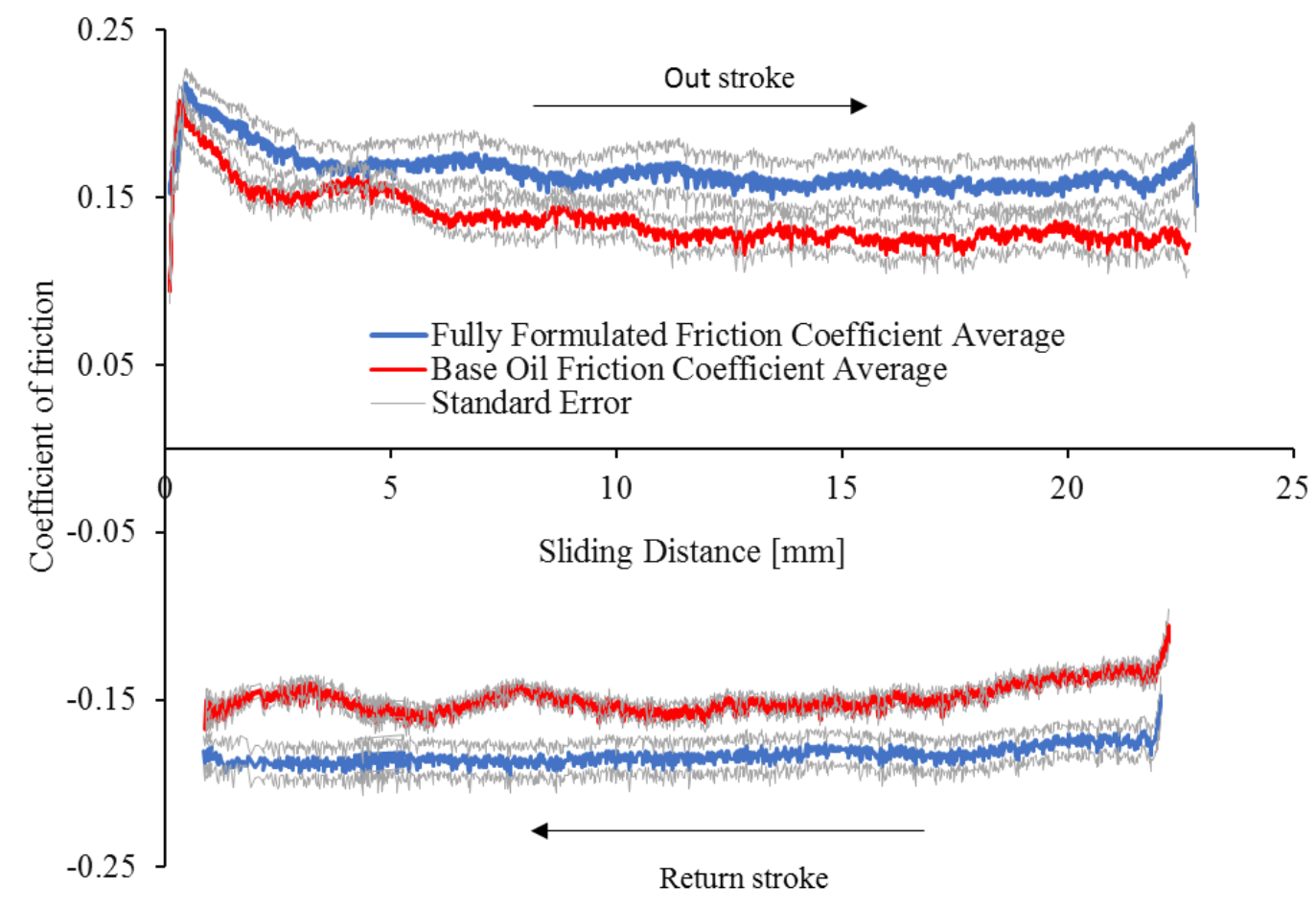

Figure 4: Measured coefficient of friction using the sliding strip tribometer with fully formulated 5 W30 lubricant and with a base oil

Noticeably, the average kinetic coefficient of friction for the base oil without any additive is lower than that of the fully formulated lubricant. In fact, the average increase in coefficient of friction for the fully-formulated lubricant across the testing speed range of $13-27 \mathrm{~mm} / \mathrm{s}$ is 0.02 .

After tribometric testing, residues of the base oil and the fully formulated lubricant were left on their respective specimen surfaces, prior to LFM measurements. The tip of the AFM probe was submerged into the fluidic residue using a fluid cell designed to keep the meniscus forces sufficiently far away from the contact [45]. Keeping the sample surface protected by a residual fluidic film protects any physically bonded film, such as an Alkyl phosphate precipitate. 


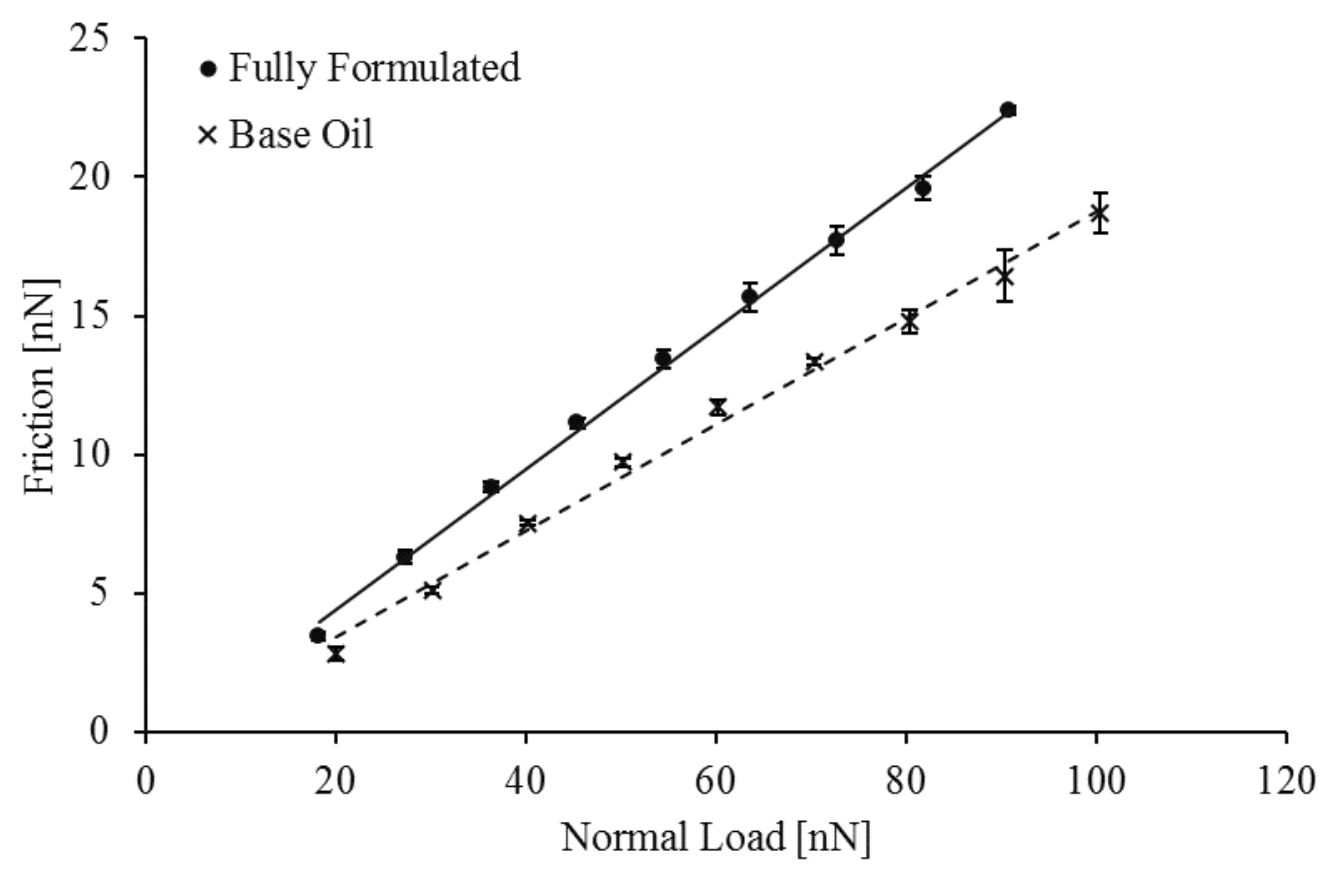

Figure 5: LFM measurements in the presence of a lubricant after tribometer testing

The variation of friction with applied contact load is shown in figure 5. Due to the intervening lubricant film, the surface energy is reduced drastically. As a result, the generated friction and contact area are both negligible at no load condition. Due to minimal adhesion in lubricated contacts, the DMT theory, used to calculate the contact area reduces to the case of classical Hertzian contact theory for point contact configuration as explained in detail in section 2.3. Thus, it is possible to calculate the contact area and the mean contact pressure.

The combination of calculated contact pressure, contact area and measured friction is used to produce a graph showing the relationship between the interfacial boundary shear strength and the normal contact pressure as shown in figure 6 . The interfacial boundary shear strength was calculated by the measured friction through LFM divided by the Hertzian contact area. The contact pressure is calculated by using equation (5) in the absence of adhesive forces (i.e. $F_{a}=0$ ). 


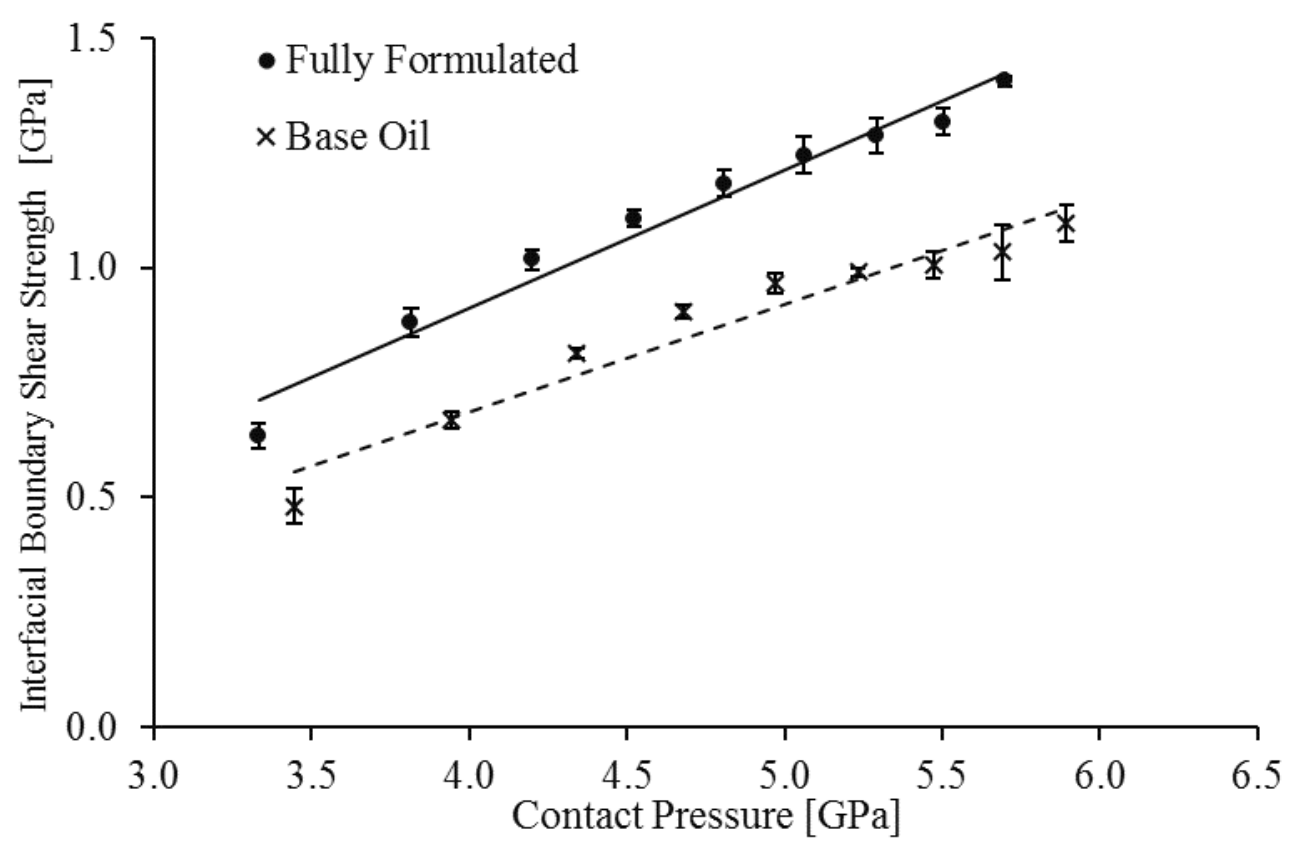

Figure 6: Interfacial boundary shear strength variation with contact pressure with wet LFM

The linear relationship between the interfacial shear strength and contact pressure has been known to apply to a multitude of confined organic molecules during sliding (equation (14) [36,67-70].

The limiting shear stress, $\tau_{0}$ [71], in equation (14) is normally in the range 1-3 MPa for engine oils under elastohydrodynamic contact conditions. The high pressures in LFM lead to diminutive films subjected to non-Newtonian shear, dominated by contact pressures, inducing shear beyond $\tau_{0}$. Thus: $\tau_{a} \cong \varsigma P[70]$. Using the results of figure 6 , the pressure coefficient of boundary shear strength, $\varsigma$ is the slope of the lines at high contact pressures. These are 0.29 for the fully-formulated lubricant and 0.23 for the case of samples with base oil. Briscoe and Thomas [36] measured values of $\varsigma$ in the range 0.10-0.95 for various poly (n-alkyl methacrylates). However, the molecular composition of the lubricants used in this study will be considerably different in this instance. The increased value of $\varsigma$ for samples with the formulated lubricant indicates the increase in boundary friction contribution which is attributed to the formation of a tribo-film. This is further investigated by removing the lubricant residue from the surface of tested specimen, using petroleum ether 40-60 wash and air dried, then comparing the frictional performance of the pre and post tribometric specimen with nominally identical surface topographies (table 2). This was ascertained through precision topographical measurements of all samples at various stages of the investigation.

The results of LFM measurements pre and post tribometry are shown in figure 7. Each of the nominally dry contact tests was carried out at 6 different locations, with an averaged value included in figure 7. The gradient of the lines represents the coefficient of friction. The coefficient of friction for the new surface (pre-tribometric) surface is 0.29 and 0.40 for post tribometry with the fully formulated lubricant. This is a further indication of the presence of a tribo-film, that increased friction, formed on the surface of the specimen subjected to mechanical activation through use of the sliding strip tribometer. 


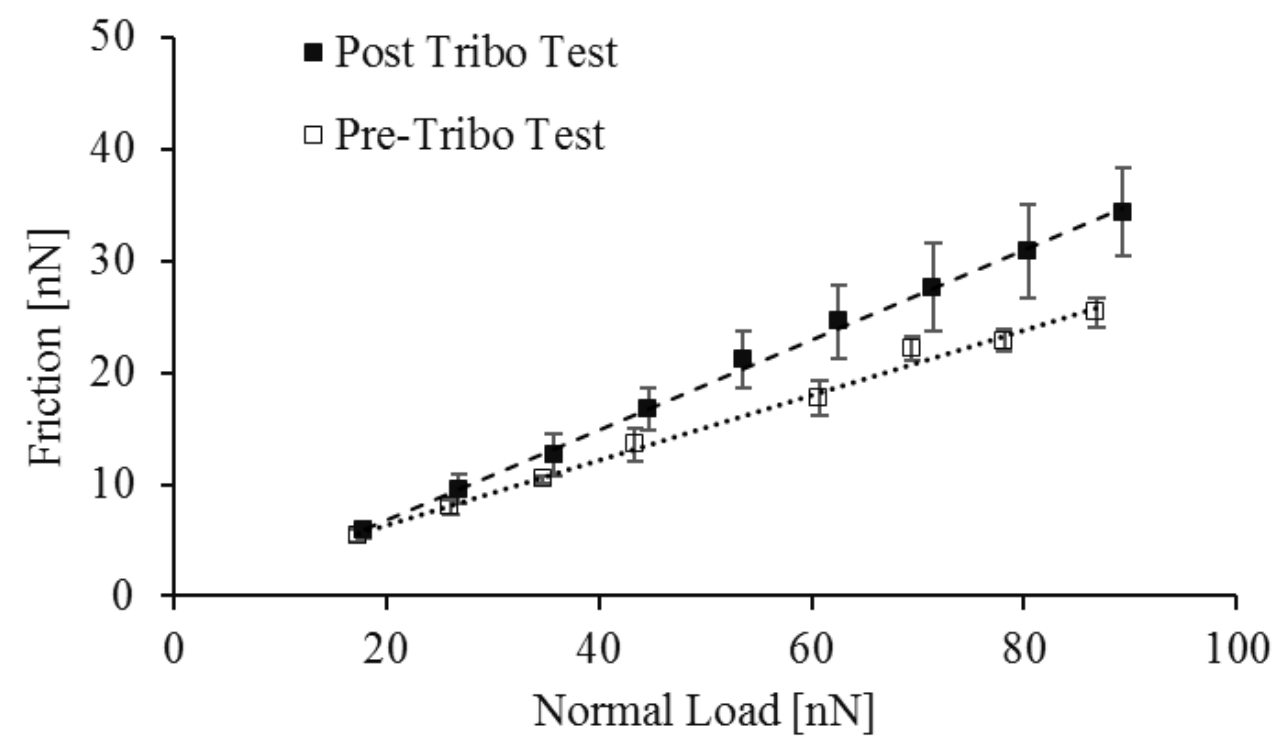

Figure 7: LFM measurements of nominally dry contact condition pre and post tribometry with the fully formulated lubricant

To determine the underlying reason for the rise in nano-scale friction, the effective Young's modulus of elasticity of the pre and post tribometric specimens determined by the procedure explained in section 2.2. These are listed in table 5.

Table 5: Measured effective Young's modulus of elasticity for the surfaces

\begin{tabular}{|l|c|c|}
\hline Reduced modulus $\left(\boldsymbol{E}^{*}\right)$ & Value & Units \\
\hline Pre tribometry & $121 \pm 6$ & $G P a$ \\
\hline Post tribometry with the fully formulated oil & $107 \pm 7$ & $G P a$ \\
\hline
\end{tabular}

The measured elastic modulus was then used to determine the contact area, contact pressure and interfacial shear strength of the AFM tip conjunction. For post-tribometric testing under dry LFM measurement, the DMT theory (section 2.4) was used to find the contact area which relates these parameters to those measured. Figure 8 shows linear variation between the boundary shear strength and the contact pressure, obtained through integrated LFM measurements and DMT contact mechanics. The boundary shear strength of the surface has clearly risen as a result of the formation of calcium-ZDDP tribofilm shown by X-ray Photoelectron Spectroscopy (XPS) of the surface (figure 9). 


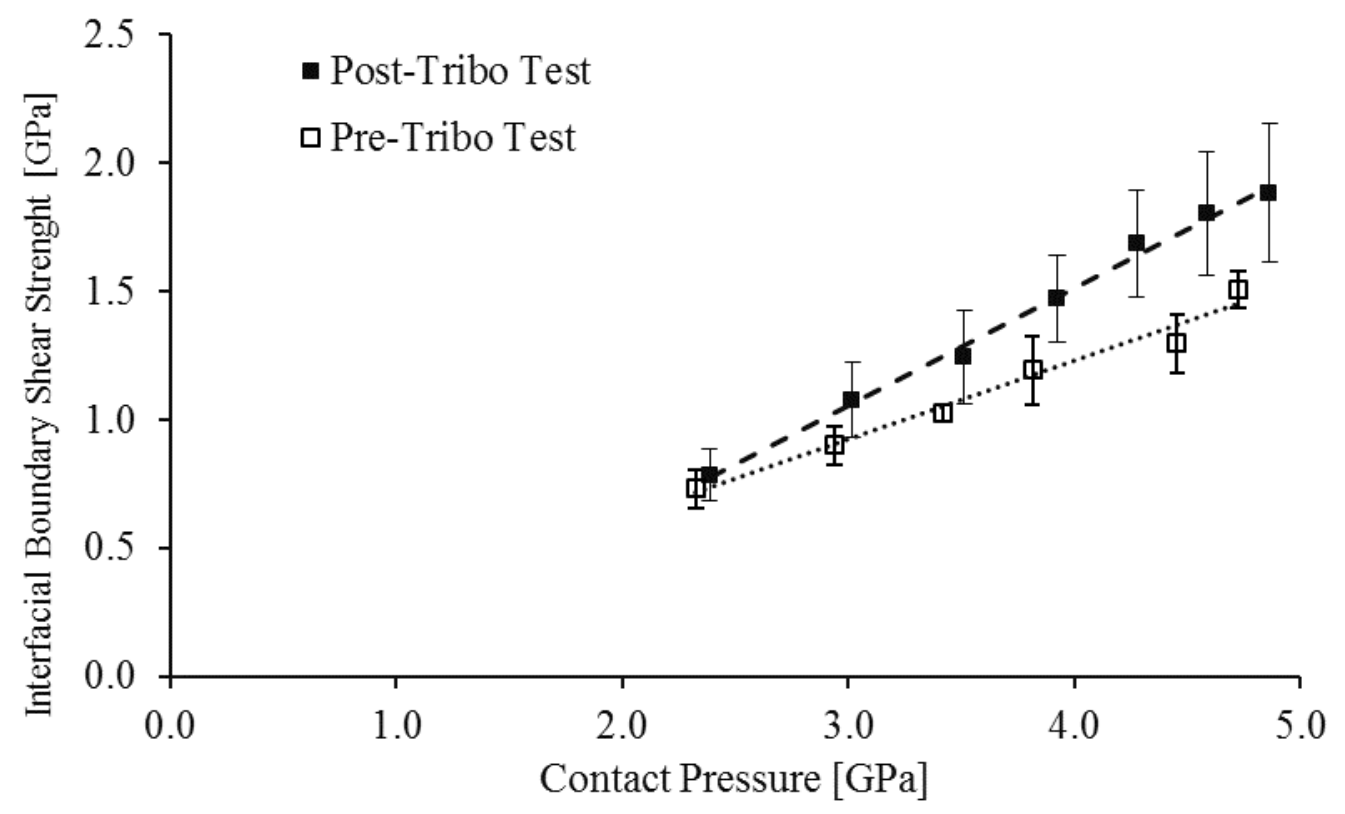

Figure 8: Interfacial boundary shear strength from integrated LFM measurements and DMT theory under nominally dry contact condition, pre and post tribometry with the fully formulated lubricant

Figure 8 shows that the pressure coefficient of boundary shear strength (gradient), $\varsigma$ increases from 0.33 for the dry new steel surface to 0.40 for the post tribo-test surface after cleaning.

To determine the presence and composition of any tribo-film formed through activation of boundary active elements in the fully formulated lubricant, a Thermo-Scientific K-Alpha XPS was used to test all the samples before and after tribometry. A combination of tribometry and XPS is widely used by researchers to generate and characterise the tribofilm on contagious surfaces [72,73]. The purpose of the XPS analysis was confined to the identification of elements that signify the presence of common additive pack components on the sample surface. Whilst a more advanced measurement procedures is available [74-77], the following was deemed to be suitable for the purpose of the current analysis. The XPS scan was conducted at 9 different locations on each of the samples. The results in figure 9 show the change in the elemental composition before and after tribometry with the fully-formulated 5W30 lubricant. The samples were washed with petroleum ether 40-60 prior to spectroscopy in order to remove any residual liquid lubricant traces. The presence of zinc, calcium, sulphur, phosphorous and nitrogen in the post-tribo test indicate the formation of a ZDDP/calcium sulphonate surface tribo-film. These elements were not present on the surface prior to tribometry. The presence of calcium and nitrogen on the surface indicates the low base synthetic alkyl benzene calcium sulphonate detergent and the high molecular weight polyisobutylene (PIB) succinimide dispersant respectively [78-80]. The detergent component within the lubricant is surface active and competes with other like components. Meanwhile, it is also likely that the high molecular weight dispersant could be entrapped in the sliding reciprocating contact in the mixed regime of lubrication and potentially, in a way, explains the presence of nitrogen. It is, therefore, clear that the increase in measured friction and boundary shear strength of the specimen surfaces, post tribometry using the fully-formulated lubricant, is as the result of a tribo-film containing ZDDP/Calcium sulphonate. This is in line with the findings of other research workers [12,15-17,81]. 


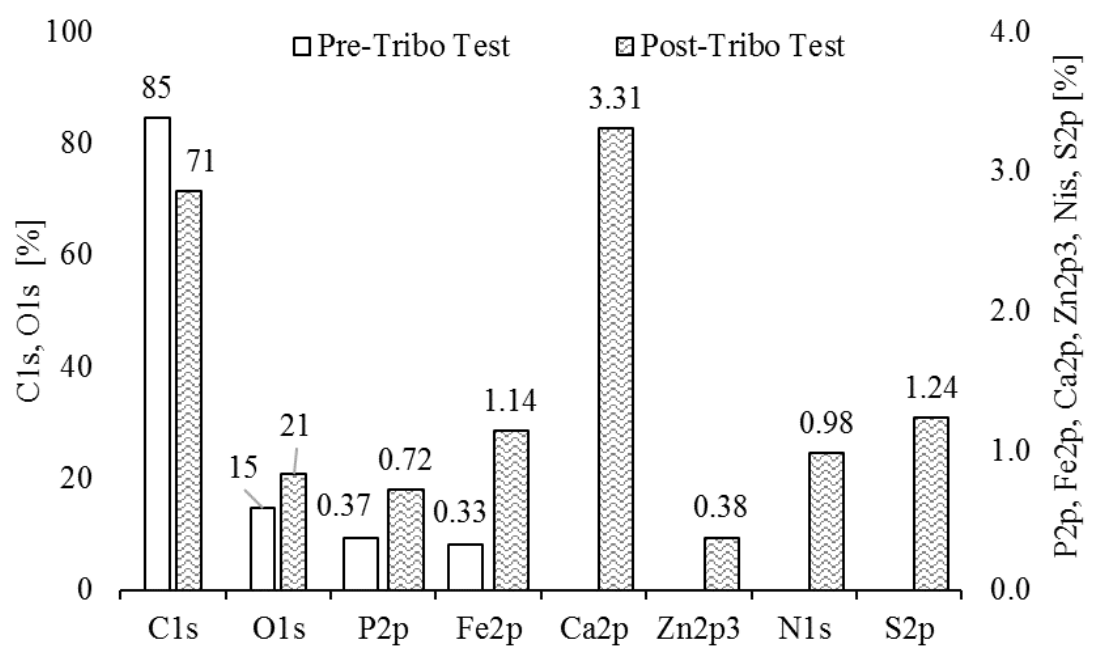

Figure 9: XPS of flat steel plate specimens for pre and post tribometry

The measured pressure coefficients of boundary shear strength are used to predict the frictional performance at the micro-scale tribometry as explained in section 2.4. The highlighted predictive methods provide a varying degree of accuracy, depending on the measurement technique used to determine the requisite input to the analysis, including the pressure coefficient of boundary shear. The measured pressure coefficient of boundary shear strength for each method of measurement is listed in table 6.

Table 6: LFM measurements of $\varsigma$

\begin{tabular}{|l|c|c|}
\hline \multicolumn{1}{|c|}{ LFM Measurement condition } & Base Oil & Fully Formulated \\
\hline $\begin{array}{l}\text { Pressure coefficient of boundary shear strength for } \\
\text { Lubricant contacts } S_{(L F M-w e t)}\end{array}$ & 0.23 & 0.29 \\
\hline $\begin{array}{l}\text { Pressure coefficient of boundary shear strength for } \\
\text { nominally post tribometric dry contacts } S_{(L F M-d r y)}\end{array}$ & 0.32 & 0.40 \\
\hline
\end{tabular}

$\varsigma$ measured with LFM is analogous, but distinct from the coefficient of friction measured by the sliding strip tribometer (section 2.1). This is because of higher contact pressures with LFM, leading to thin films in non-Newtonian shear. With the sliding strip tribometry, the regime of lubrication is predominantly mixed hydrodynamics. However, it is instructive to ascertain the degree of conformance of micro-scale predictions, based on measured $\varsigma$ values with the measured friction through inertial dynamics of the floating plate arrangement of the tribometer. In fact, the results in figure 10 clearly show that the measured value of $\varsigma$ in the presence of a lubricant is more pertinent for predicting micro-scale tribometric conditions. The error bars indicate \pm 1 standard deviation in the experimental data. When the measured value of $\varsigma$ for nominally dry surfaces is used, it leads to an over-estimated prediction of micro-scale conditions.

It has been shown that under severe conditions, where physically-adsorbed layers may be removed completely or partially during the sliding process, the results obtained from dry LFM for the pressure coefficient of boundary shear strength may be more deemed to be more appropriate [82]. However, the changes in the frictional behaviour in micro-scale can also be linked to the changes in the surface topography resulting from the removal of the surface-adsorbed layers. 


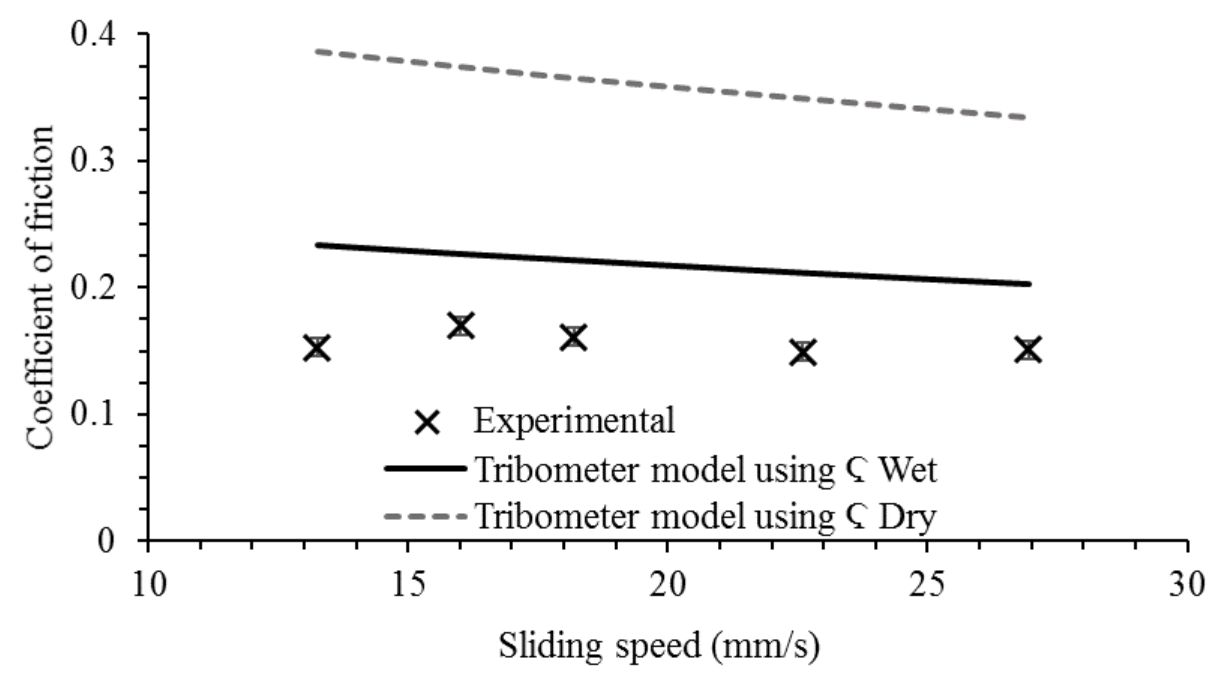

(a)

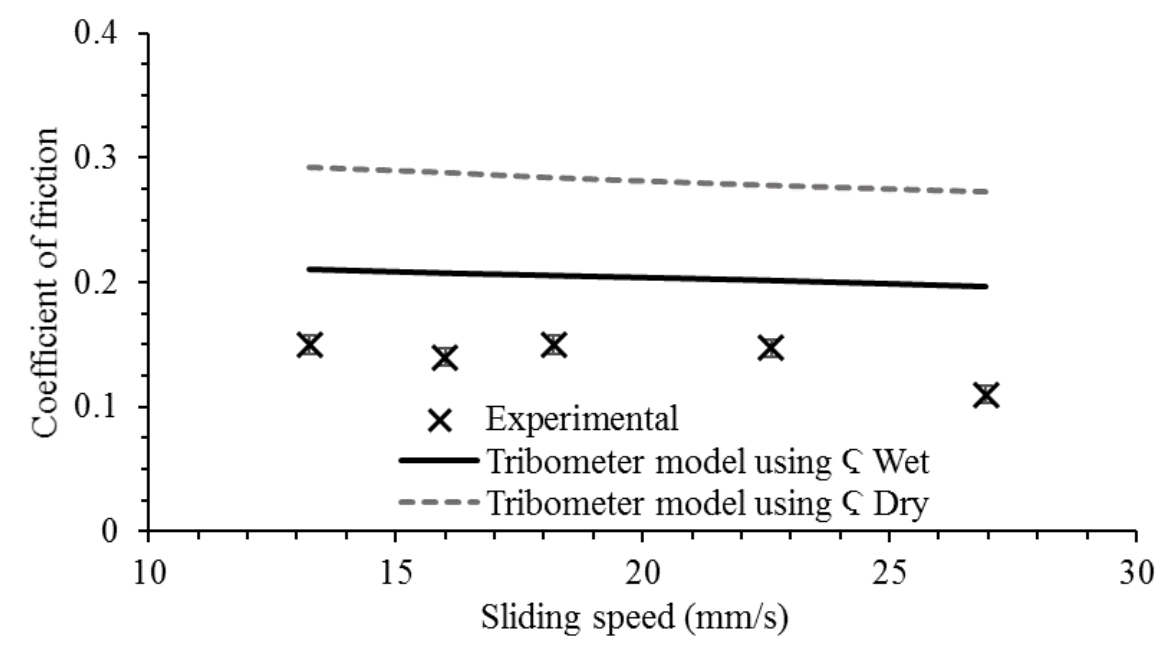

(b)

Figure 10: Predicted and measured coefficient of friction variation with sliding velocity using LFM measured $\varsigma$ in the presence: (a) fully formulated lubricant, and (b) base oil

\section{Concluding Remarks}

This paper explains the development of a combined experimental and analytical procedure to investigate frictional characteristics of generated tribofilm derived from a fully formulated engine oil at both micro and nano-scales. The paper also highlights the importance of boundary shear strength of a tribofilm in providing an explanation for the observed rise in friction due to adsorbed ZDDP-based tribofilms, as well as linking the frictional characteristics at nano-scale to measured friction in the micro-scale. It is demonstrated that the fluid cell method is a useful tool in determining the pressure coefficients of boundary shear strength of wetted surfaces. In this study both dry and wet LFM are used to measure the pressure coefficient of boundary shear strength specific for the generated tribofilm. It is shown that this parameter is crucial in predicting friction in the micro-scale contact analysis, and can be measured directly using LFM in the nano-scale. LFM measurements in the absence of a fluid (dry LFM) are shown to over-predict the pressure coefficient of boundary shear strength. 
The tribofilm derived from the fully-formulated engine oil is measured on the surface using XPS, showing a slight increase in friction during the tests with the LFM in comparison with the virgin steel sample. The results also show higher friction for the fully-formulated lubricant in comparison with the base oil in both LFM and the tribometric tests. This explains the measured high friction for the ZDDP-based tribofilms in the current study and more widely in the literature [12, 13, 15-17], particularly when it is coupled with a decrease in the composite Young's modulus of elasticity of the surface as well as an increase in the pressure coefficient of boundary shear strength of the contact reported here.

\section{Acknowledgements}

The authors would like to express their gratitude to the Engineering and Physical Sciences Research Council (EPSRC), Castrol Ltd. and UET Lahore under the Faculty Development Program, for the financial support provided to this reported research. The authors also acknowledge use of facilities within the Loughborough Materials Characterisation Centre (LMCC).

\section{Appendix}

The statistical functions $\left(\mathrm{F}_{2}\right.$ and $\left.\mathrm{F}_{5 / 2}\right)$ required for the Greenwood and Tripp model have been applied using a curve fit to the measured peak height distributions. Two $6^{\text {th }}$-order polynomials of the form $F_{n}(\lambda)=a_{6} \lambda^{6}+a_{5} \lambda^{5}+a_{4} \lambda^{4}+a_{3} \lambda^{3}+a_{2} \lambda^{2}+a_{1} \lambda+a_{0}$ were used to accurately fit the entire range between the lubricant film ratios $(\lambda)$ of 2 and 6 . The coefficients are provided below:

Table 7: $F_{2}$ and $F_{5 / 2}$ polynomial curve fit parameters

\begin{tabular}{|l|c|c|c|c|}
\hline & $\boldsymbol{F}_{\mathbf{5} / \mathbf{2}}$ for $\mathbf{2}>\boldsymbol{\lambda}>\mathbf{4 . 1}$ & $\boldsymbol{F}_{\mathbf{5 / 2}}$ for $\mathbf{4 . 1}>\boldsymbol{\lambda}>\mathbf{6}$ & $\boldsymbol{F}_{\mathbf{2}}$ for $\mathbf{2}>\boldsymbol{\lambda}>\mathbf{4 . 1}$ & $\boldsymbol{F}_{\mathbf{2}}$ for $\mathbf{4 . 1}>\boldsymbol{\lambda}>\mathbf{6}$ \\
\hline $\boldsymbol{a}_{\mathbf{0}}$ & 4.39 & 1.22 & 3.01 & 1.27 \\
\hline $\boldsymbol{a}_{\mathbf{1}}$ & 5.77 & -1.37 & -3.60 & -1.41 \\
\hline $\boldsymbol{a}_{\mathbf{2}}$ & 3.20 & 0.64 & 1.75 & 0.65 \\
\hline $\boldsymbol{a}_{\mathbf{3}}$ & -0.95 & -0.16 & -0.43 & -0.16 \\
\hline $\boldsymbol{a}_{\mathbf{4}}$ & 0.16 & $2.22 \times 10^{-2}$ & $5.54 \times 10^{-2}$ & $2.27 \times 10^{-2}$ \\
\hline $\boldsymbol{a}_{\mathbf{5}}$ & $-1.43 \times 10^{-2}$ & $-1.67 \times 10^{-3}$ & $-3.07 \times 10^{-3}$ & $-1.69 \times 10^{-3}$ \\
\hline $\boldsymbol{a}_{\mathbf{6}}$ & $5.32 \times 10^{-4}$ & $5.20 \times 10^{-5}$ & $2.55 \times 10^{-5}$ & $5.26 \times 10^{-5}$ \\
\hline
\end{tabular}

\section{References}

[1]- Holmberg, K., Andersson, P. and Erdemir, A., "Global energy consumption due to friction in passenger cars", Tribology Int., 2012, 47, pp. 221-234.

[2]- Fitzsimons, B., "Introduction to the importance of fuel efficiency and role of the Encyclopaedic research project", IMechE Seminar: A Drive for fuel efficiency, Loughborough, UK, 2011.

[3]- Uras, H.M. and Patterson, D.J., "Measurement of piston and ring assembly friction instantaneous IMEP method", SAE Technical Paper, No. 830416, 1983.

[4]- Gore, M., Rahmani, R., Rahnejat, H. and King, P. D., "Assessment of friction from compression ring conjunction of a high-performance internal combustion engine: A combined numerical and experimental study", Proc. IMechE, Part C: J. Mechanical Engineering Science, 2016, 230(12), pp. 2073-2085. 
[5]- Richardson, D. E., "Review of power cylinder friction for diesel engines", Trans. ASME, J. Engineering for Gas Turbines and Power, 2000, 122(4), pp. 506-519.

[6]- Morris, N., Leighton, M., De la Cruz, M., Rahmani, R., Rahnejat, H. and Howell-Smith, S., "Combined numerical and experimental investigation of the micro-hydrodynamics of chevron-based textured patterns influencing conjunctional friction of sliding contacts", Proc. IMechE, Part J: J. Engineering Tribology, 2015, 229(4), pp. 316-335.

[7]- Castleman Jr, R. A., "A hydrodynamical theory of piston ring lubrication", Physics, 1936, 7(9), pp. 364-367.

[8]- Baker, C. E., Theodossiades, S., Rahnejat, H. and Fitzsimons, B., "Influence of in-plane dynamics of thin compression rings on friction in internal combustion engines", J. Engineering for Gas Turbines and Power, 2012, 134(9): 092801.

[9]- Lenauer, C., Tomastik, C., Wopelka, T. and Jech, M., "Piston ring wear and cylinder liner tribofilm in tribotests with lubricants artificially altered with ethanol combustion products", Tribology Int., 2015, 82, pp. 415-422.

[10]- Studt, P., "Boundary lubrication: adsorption of oil additives on steel and ceramic surfaces and its influence on friction and wear", Tribology Int., 1989, 22(2), pp. 111-119.

[11]- Hsu, S.M., "Molecular basis of lubrication", Tribology Int., 2004, 37(7), pp. 553-559.

[12]- Spikes, H., “The history and mechanisms of ZDDP”, Tribology letters, 2004, 17(3), pp. 469489 .

[13]- Larson, R., "The performance of zinc dithiophosphates as lubricating oil additives", Industrial Lubrication and Tribology, 1958, 10(8), pp. 12-19.

[14]- Bidwell, J. B., and R. K. Williams, "The new look in lubricating oils", SAE Tech. Paper, No. $550258,1955$.

[15]- Muraki, M., Yanagi, Y. and Sakaguchi, K., "Synergistic effect on frictional characteristics under rolling-sliding conditions due to a combination of molybdenum dialkyldithiocarbamate and zinc dialkyldithiophosphate", Tribology Int., 1997, 30(1), pp. 69-75.

[16]- Taylor, L., Dratva, A. and Spikes, H.A., "Friction and wear behavior of zinc dialkyldithiophosphate additive", Tribology Trans., 2000, 43(3), pp.469-479.

[17]- Taylor, L. J. and Spikes, H. A., "Friction-enhancing properties of ZDDP antiwear additive: part I-friction and morphology of ZDDP reaction films", Tribology Trans., 2003, 46(3), pp. 303-309.

[18]- Pidduck, A.J. and Smith, G.C., "Scanning probe microscopy of automotive anti-wear films", Wear, 1997, 212(2), pp. 254-264.

[19]- Warren, O. L., J. F. Graham, Norton, P. R., Houston, J. E. and Michalske, T. A., "Nanomechanical properties of films derived from zinc dialkyldithiophosphate", Tribology Letters, 1998, 4(2), pp. 189-198. 
[20]- Graham, J.F., McCague, C. and Norton, P.R., "Topography and nanomechanical properties of tribochemical films derived from zinc dialkyl and diaryl dithiophosphates", Tribology letters, 1999, 6(3), pp. 149-157.

[21]- Aktary, M., McDermott, M.T. and McAlpine, G.A., "Morphology and nanomechanical properties of ZDDP antiwear films as a function of tribological contact time", Tribology letters, 2002, 12(3), pp. 155-162.

[22]- Aktary, M., McDermott, M.T. and Torkelson, J., "Morphological evolution of films formed from thermooxidative decomposition of ZDDP", Wear, 2001, 247(2), pp. 172-179.

[23]- Bec, S.A., Tonck, A., Georges, J.M., Coy, R.C., Bell, J.C. and Roper, G.W., "Relationship between mechanical properties and structures of zinc dithiophosphate anti-wear films", Proc. Roy. Soc., Ser. A, 1992, 455, pp. 4181-4203.

[24]- Carpick, R.W., Agrait, N., Ogletree, D.F. and Salmeron, M., "Measurement of interfacial shear (friction) with an ultrahigh vacuum atomic force microscope", J. Vacuum Science and Tech., B: Microelectronics and Nanometer Structures Processing, Measurement, and Phenomena, 1996, 14(2), pp. 1289-1295.

[25]- Enachescu, M., Van den Oetelaar, R. J. A., Carpick, R. W., Ogletree, D. F., Flipse, C. F. J. and Salmeron, M., "Observation of proportionality between friction and contact area at the nanometer scale", Tribology Letters, 1999, 7(2-3), p. 73.

[26]- Lantz, M.A., O'shea, S.J., Welland, M.E. and Johnson, K.L., “Atomic-force-microscope study of contact area and friction on NbSe2", Physical Review B, 1997, 55(16):10776.

[27]- Derjaguin, B.V., Muller, V. M. and Toporov, Y.P., "Effect of contact deformations on the adhesion of particles", J. Colloid and Interface Science, 1975, 53(2), pp. 314-326.

[28]- Johnson, K. L., Kendall, K. and Roberts, A. D., "Surface energy and the contact of elastic solids", Proc. Roy. Soc., Series A, 1971, 324 (1558), pp. 301-313.

[29]- Maugis, D., "Adhesion of spheres: the JKR-DMT transition using a Dugdale model", J. Colloid and Interface Science, 1992, 150(1), pp. 243-269.

[30]- Umer, J., Morris, N., Leighton, M., Rahmani, R., Howell-Smith, S., Wild, R. and Rahnejat, H., "Asperity level tribological investigation of automotive bore material and coatings", Tribology Int., 2018, 117, pp. 131-140.

[31]-Pereira, G., Munoz-Paniagua, D., Lachenwitzer, A., Kasrai, M., Norton, P.R., Capehart, T.W., Perry, T.A. and Cheng, Y.T., "A variable temperature mechanical analysis of ZDDP-derived antiwear films formed on 52100 steel”, Wear, 2007, 262, pp. 461-470

[32]- Nicholls, M.A., Do, T., Norton, P.R., Bancroft, G.M., Kasrai, M., Capehart, T.W., Cheng, Y.T. and Perry, T., "Chemical and mechanical properties of ZDDP antiwear films on steel and thermal spray coatings studied by XANES spectroscopy and nanoindentation techniques", Tribology Letters, 2003, 15(3), pp.241-248.

[33]- Yoon, E.S., Singh, R.A., Oh, H.J. and Kong, H., "The effect of contact area on nano/micro-scale friction", Wear, 2005, 259(7-12), pp.1424-1431. 
[34]- Ruan, J.A. and Bhushan, B., "Atomic-scale and microscale friction studies of graphite and diamond using friction force microscopy”, Journal of Applied Physics, 1994 76(9), pp.5022-5035.

[35]- Koinkar, V.N. and Bhushan, B., "Effect of scan size and surface roughness on microscale friction measurements", Journal of Applied Physics, 1997, 81(6), pp.2472-2479.

[36]- Briscoe, B.J. and Thomas, P.S., "Friction Energy Dissipation in Organic Films", Tribology and Interface Series, Elsevier, 1994, 27, pp. 193-202.

[37]- Leighton, M., Morris, N., Gore, M., Rahmani, R., Rahnejat, H. and King, P.D., "Boundary interactions of rough non-Gaussian surfaces", Proc. IMechE, Part J: J. Engineering Tribology, 2016, 230(11), pp. 1359-1370.

[38]- Gore, M., Morris, N., Rahmani, R., Rahnejat, H., King, P. D. and Howell-Smith, S., "A combined analytical-experimental investigation of friction in cylinder liner inserts under mixed and boundary regimes of lubrication", Lubrication Science, 2017, 29(5), pp. 293-316.

[39]- Leighton, M., Morris, N., Rahmani, R. and Rahnejat, H., "Surface specific asperity model for prediction of friction in boundary and mixed regimes of lubrication", Meccanica, 2017, 52(1-2), pp. 21-33.

[40]- Bird, R.J. and Galvin, G.D., "The application of photoelectron spectroscopy to the study of EP films on lubricated surfaces", Wear, 1976, 37(1), pp. 143-167.

[41]- Gosvami, N.N., Bares, J.A., Mangolini, F., Konicek, A.R., Yablon, D.G. and Carpick, R.W., "Mechanisms of antiwear tribofilm growth revealed in situ by single-asperity sliding contacts", Science, 2015, 348(6230), pp. 102-106.

[42]- Akchurin, A. and Bosman, R., "A Deterministic Stress-Activated Model for Tribo-Film Growth and Wear Simulation", Tribology Letters, 2017, 65(2):59.

[43]- Michalski, J. and Woś, P., "The effect of cylinder liner surface topography on abrasive wear of piston-cylinder assembly in combustion engine", Wear, 2001, 271(3-4), pp.582-589

[44]- Chong, W.W.F and Rahnejat, H., "Nanoscale friction as a function of activation energies", Surface Topography: Metrology and Properties, 2015, 3(4):044002.

[45]-ASTM standard D445. Standard test method for kinematic viscosity of transparent and opaque liquids. ASTM, West Conshohocken, PA

[46]- Zhou, Z.F., Li, K.Y., Bello, I., Lee, C.S. and Lee, S.T., "Study of tribological performance of ECR-CVD diamond-like carbon coatings on steel substrates: Part 2. The analysis of wear mechanism", Wear, 2005, 258(10), pp.1589-1599.

[47]- Bhushan, B. and Ruan, J.A., "Atomic-scale friction measurements using friction force microscopy: part II—application to magnetic media”, J. Tribology, 1994, 116(2), pp.389-396.

[48]- Fang, T.H. and Chang, W.J., "Effects of AFM-based nanomachining process on aluminium surface", J. Physics and Chemistry of Solids, 2003, 64(6), pp.913-918.

[49]- Bhushan, B., "Introduction to Tribology”, John Wiley \& Sons, 2013 
[50]- Carpick, R. W., Agrait, N., Ogletree, D. F. and Salmeron, M., "Variation of the interfacial shear strength and adhesion of a nanometer-sized contact", Langmuir, 1996, 12(13), pp. 3334-3340.

[51]- Landman, U., Luedtke, W. D. and Nitzan, A., "Dynamics of tip-substrate interactions in atomic force microscopy", Surface Science Letters, 1989, 210(3): L177-L184.

[52]- Leighton, M., Nicholls, T., De la Cruz, M., Rahmani, R. and Rahnejat, H., "Combined lubricant-surface system perspective: Multi-scale numerical-experimental investigation", Proc. IMechE, Part J: J. Engineering Tribology, 2017, 231(7), pp. 910-924.

[53]- Ruan, J. A. and Bhushan, B., "Atomic-scale friction measurements using friction force microscopy: part I-general principles and new measurement techniques", Trans. ASME, J. Tribology, 1994, 116(2), pp. 378-388.

[54]- Chong, W.W.F., Teodorescu, M. and Rahnejat, H., "Nanoscale elastoplastic adhesion of wet asperities”, Proc. IMechE, Part J: J. Engineering Tribology, 2013, 227(9), pp. 996-1010.

[55]- Campen, S., Green, J.H., Lamb, G.D. and Spikes, H.A., "In situ study of model organic friction modifiers using liquid cell AFM; saturated and mono-unsaturated carboxylic acids", Tribology Letters, 2015, 57(2):18

[56]- Campen, S., Green, J.H., Lamb, G.D. and Spikes, H.A., "In Situ Study of Model Organic Friction Modifiers Using Liquid Cell AFM: Self-Assembly of Octadecylamine", Tribology Letters, 2015, 58(3):39

[57]- Buenviaje, C.K., Ge, S-R, Rafaillovich, M.H. and Overney, R.M., "Atomic force microscopy calibration methods for lateral force, elasticity, and viscosity", Proc. Mater. Res. Soc. Symp., 1998, 522, pp. 187-192.

[58]- Bradley, R.S., "The cohesive force between solid surfaces and the surface energy of solids", London, Edinburgh, and Dublin Phil. Magazine and J. Science, 1932, 13(86), pp. 853-862.

[59]- Johnson, K. L. and Greenwood, J. A., "An adhesion map for the contact of elastic spheres", J. Colloid and Interface Science, 1997, 192(2), pp. 326-333.

[60]- Tabor, D., "Surface forces and surface interactions", J. Colloid and Interface Science, 1977, 58(1), pp. 2-13.

[61]- Riedo, E., Le'vy, F. and Brune, H., "Kinetics of capillary condensation in nanoscopic sliding friction ”, Physical Review Letters, 2002, 88(18), p.185505

[62]- Teodorescu, M. and Rahnejat, H., "Dry and wet nano-scale impact dynamics of rough surfaces with or without a self-assembled monolayer", Proc. IMechE, Part N: J. Nanoengineering and Nanosystems, 2007, 221(2), pp. 49-58.

[63]- Gohar, R. and Rahnejat, H., "Fundamentals of Tribology", Imperial College Press, London, 2008

[64]- Greenwood, J. A., and Tripp, J. H., "The contact of two nominally flat rough surfaces", Proc. IMechE, 185(1), 1970, pp. 625-633. 
[65]- Teodorescu, M., Balakrishnan, S. and Rahnejat, H., "Integrated tribological analysis within a multi-physics approach to system dynamics", In Tribology and Interface Engineering Series, Elsevier, 2005, 48 , pp. $725-737$

[66]- Rahmani, R., Theodossiades, S., Rahnejat, H. and Fitzsimons, B., "Transient Elastohydrodynamic Lubrication of Rough New or Worn Piston Compression Ring Conjunction with an Out-of-Round Cylinder Bore", Proc. IMechE, Part J: J. Engineering Tribology, 2012, 226(4), pp. 284-305

[67]- Briscoe, B. J., and Evans, D. C. B., "The shear properties of Langmuir-Blodgett layers", Proc. Roy. Soc., Series A, 1982, 380(1779), pp. 389-407

[68]- Bridgeman, P. G., "Pressure Effect on hydrocarbons", Proc. American Acad. Arts Sci., 1936, 71, p. 387.

[69]- Briscoe, B. J., "Friction of organic polymers", In Fundamentals of friction: macroscopic and microscopic processes, pp. 167-182, Springer, Netherlands, 1992.

[70]- Dowson, D., "Elastohydrodynamic and micro-elastohydrodynamic lubrication", Wear, 1995, 190(2), pp.125-138.

[71]- Eyring, H., "Viscosity, plasticity, and diffusion as examples of absolute reaction rates", J. chemical physics, 1936, 4(4), pp. 283-291.

[72]- Haque, T., Morina, A., Neville, A., Kapadia, R. and Arrowsmith, S., "Study of the ZDDP antiwear tribofilm formed on the DLC coating using AFM and XPS techniques", J. ASTM International, 2007, 4(7), pp.1-11.

[73]- de Barros' Bouchet, M.I., Martin, J.M., Le-Mogne, T. and Vacher, B., 2005, "Boundary lubrication mechanisms of carbon coatings by MoDTC and ZDDP additives", Tribology International, 2005, 38(3), pp.257-264.

[74]- Rokosz, K., Lahtinen, J., Hryniewicz, T. and Rzadkiewicz, S., "XPS depth profiling analysis of passive surface layers formed on austenitic AISI 304L and AISI 316L SS after high-current-density electropolishing", Surface and Coatings Technology, 2015, 276, pp.516-520.

[75]- Ghods, P., Isgor, O.B., Brown, J.R., Bensebaa, F. and Kingston, D., "XPS depth profiling study on the passive oxide film of carbon steel in saturated calcium hydroxide solution and the effect of chloride on the film properties”, Applied Surface Science, 2011, 257(10), pp.4669-4677

[76]-Minfray, C., Martin, J.M., Esnouf, C., Le Mogne, T., Kersting, R. and Hagenhoff, B., "A multitechnique approach of tribofilm characterisation", Thin Solid Films, 2004, 447, pp.272-277

[77]- Tarasov, S., Kolubaev, A., Belyaev, S., Lerner, M. and Tepper, F., "Study of friction reduction by nanocopper additives to motor oil”, Wear, 2002, 252(1-2), pp.63-69.

[78]- Greenall, A., Neville, A., Morina, A. and Sutton, M., "Investigation of the interactions between a novel, organic anti-wear additive, ZDDP and overbased calcium sulphonate", Tribology International, 2012, 46(1), pp.52-61.

[79]- Pereira, G., Lachenwitzer, A., Kasrai, M., Bancroft, G.M., Norton, P.R., Abrecht, M., Gilbert, P.U.P.A., Regier, T., Blyth, R.I.R. and Thompson, J., "Chemical and mechanical analysis of 
tribofilms from fully formulated oils Part 1-Films on 52100 steel", Tribology-Materials, Surfaces \& Interfaces, 2007, 1(1), pp.48-61.

[80]- Cizaire, L., Martin, J.M., Gresser, E., Dinh, N.T. and Heau, C., "Tribochemistry of overbased calcium detergents studied by ToF-SIMS and other surface analyses", Tribology Letters, 2004, 17(4), pp.715-721.

[81]- Kapsa, P., Martin, J.M., Blanc, C. and Georges, J.M., "Antiwear mechanism of ZDDP in the presence of calcium sulfonate detergent”, Trans. ASME, J. Lubrication Tech., 1981, 103(4), pp. 486494.

[82]- Humphrey, E., Morris, N., Leighton, M., Rahmani, R. and Rahnejat, H., "Multiscale friction in lubricant-surface systems for high-performance transmissions under mild wear", Tribology Letters, 2018, 66 (3), 77. 